\title{
Procesos CONSTITUYENTES Y REFUNDACIÓN DEMOCRÁticA. El CASO dE CHILE EN PERSPECTIVA COMPARADA*
}

\author{
Constituent Processes and Democratic Refoundation. The Case \\ of Chile in Comparative Perspective
}

\section{GABRIEL L. NEGRETTO}

Centro de Investigación y Docencia Económicas

Tanto en la teoría política como constitucional, la abrumadora mayoría de los análisis sobre la creación de constituciones toma como perspectiva la idea de un nuevo comienzo político, sea que refiera a la revolución que funda el primer gobierno republicano en un país, o a la transición de un régimen autoritario a uno democrático. Sin embargo, es posible que un proceso constituyente irrumpa dentro de un orden democrático ya constituido. Esto puede ocurrir porque aspectos básicos de la constitución vigente se han tornado disfuncionales en una coyuntura histórica dada o porque la sociedad ha experimentado cambios que hacen cuestionable el origen y la orientación política del texto constitucional.

Es intuitivo pensar que en un régimen democrático establecido el proceso constituyente debiera ser distinto al que tendría lugar en una revolución o en una transición a la democracia. Específicamente, sería de esperar que en el contexto de una democracia constitucional la creación de una nueva constitución se hiciera de acuerdo con reglas preestablecidas. Sin embargo, la mayor parte de las constituciones excluyen esta posibilidad al dejar sin regular su propio reemplazo y no permitir a la ciudadanía peticionarlo. Esta situación genera un dilema legal y político en todo país donde se cuestionan los principios fundamentales de la constitución vigente y se exige el involucramiento de los ciudadanos en la definición del nuevo orden constitucional. Este dilema ha sido enfrentado con distinta suerte por varios países de América Latina en años recientes: Colombia (19901991), Ecuador (1997-1998 y 2007-2008), Venezuela (1998-1999) y Bolivia (2006-2009). Asimismo, la discusión constituyente se ha instalado actualmente en países como Chile y Panamá, que han transitado a la democracia con constituciones sancionadas en una dictadura y que lógicamente no fueron pensadas para ser reemplazadas fácilmente.

El objetivo de este ensayo es analizar, desde la teoría y la experiencia constitucional comparada, el problema de cómo crear una nueva constitución dentro de un orden democrático cuando la constitución vigente no prevé un procedimiento para su reemplazo.

* El presente ensayo es una versión extendida de la conferencia magistral ofrecida por el autor en la Universidad Alberto Hurtado de Santiago de Chile, para la clausura del XI Congreso Chileno de Ciencia Política “Política, diversidad y conflicto: nuevos debates a 30 años de la $\mathrm{ACCP}^{\prime \prime}$, el día 17 de octubre de 2014. 
Me enfocaré específicamente en la selección del órgano constituyente y en los canales de participación popular con el fin de ofrecer algunas reflexiones sobre el caso de Chile. Discutiré las alternativas que existen tomando en cuenta su legitimidad democrática y su institucionalidad, que entenderé como el grado de apropiación de la nueva constitución por parte de la ciudadanía como su obra colectiva y el nivel de legalidad y consenso con que se regula el proceso. Esta perspectiva no solo resume las características que el actual gobierno de Chile pretende dar a la elaboración de la nueva constitución, sino que refleja muy bien los problemas que enfrenta cualquier país que busca reemplazar democráticamente su constitución cuando esta última no contempla esa posibilidad.

\section{EL PODER CONSTITUYENTE COMO PODER EXTRACONSTITUCIONAL}

Un principio central del constitucionalismo moderno es que la legitimidad y la validez de una constitución deriva de haber sido creada con la autorización o el consentimiento de los gobernados. ${ }^{1}$ Sin embargo, y quizás paradójicamente, la mayoría de las constituciones del mundo contradicen este principio y sus propios fundamentos democráticos al negar al pueblo la capacidad legal de decidir directamente sobre la vigencia y contenido de la carta fundamental. Casi todas las constituciones incluyen un procedimiento especial para su revisión parcial por medio de la asamblea legislativa. Algunas pocas permiten ser reformadas en su totalidad por la legislatura ordinaria o por una convención especial. Pero curiosamente es muy raro encontrar constituciones que autoricen a los ciudadanos a activar o ratificar un proceso constituyente dirigido a reemplazarlas.

La idea de que el poder constituyente del pueblo da validez y autoridad a una constitución, pero que luego del acto fundacional debe desaparecer y ser reemplazado por los órganos constituidos fue articulada con claridad en la teoría constitucional de James Madison. En el Federalista \#40, Madison argumentó que la legitimidad de la constitución de Filadelfia no residía en haber sido aprobada siguiendo los procedimientos establecidos por la constitución entonces vigente (que a todas luces fueron violados), sino en su eventual ratificación por el pueblo reunido en convenciones estatales elegidas al efecto. Según Madison, esto es así pues toda vez que grandes cambios son necesarios, un apego estricto a las formas legales podría hacer imposible ejercitar el "trascendente y precioso derecho" del pueblo de abolir o alterar sus gobiernos como mejor le convenga. ${ }^{2}$ En todo caso, cualquier posible irregularidad quedaría subsanada por el consentimiento del pueblo, que es el único autor legítimo de la constitución.

Frente al argumento de que la validez de la nueva constitución descansaba en el derecho inalienable del pueblo a crear o abolir su forma de gobierno, podría pensarse entonces que el cuerpo ciudadano retendría la prerrogativa de actuar para proteger la constitución contra los abusos de sus representantes, de peticionar su alteración o reemplazo, o

1 Thomas Paine sintetizó muy bien este principio al afirmar que la constitución de un país "no es un acto de su gobierno, sino del pueblo que constituye a su gobierno". Ver Paine (1791) [1995]: 468.

2 Ver Madison, Hamilton and Jay (1788 [1987]): 264. 
de consentir estos cambios cuando sean propuestos por los poderes constituidos. Sin embargo, como lo deja en claro Madison en El Federalista \#49, semejante conclusión pondría en riesgo la estabilidad futura de la constitución. Por ello, el modelo de gobierno constitucional propuesto por los Federalistas buscó hacer innecesaria la participación del pueblo para corregir abusos constitucionales por medio de un sistema autorregulado de frenos y contrapesos y relegó el derecho colectivo del pueblo a alterar o reemplazar la constitución a momentos de excepción que no deben ser previstos por la constitución.

Esta filosofía quedó reflejada en el artículo V de la constitución estadounidense, el cual puso exclusivamente en manos de los poderes legislativos constituidos, federales o locales, la capacidad de proponer enmiendas a la constitución. Aunque dicho artículo prevé el llamado a una convención, esta no puede ser convocada, sino por dos terceras partes de las legislaturas de los estados. En distintas variantes, este sistema se trasladó a la mayor parte de las constituciones del mundo y el positivismo legal lo reafirmó, relegando el ejercicio del poder constituyente a un acto cuyo sustento es puramente fáctico y por tanto no puede ser regulado de antemano y de manera general por la constitución vigente.

Curiosamente, la teoría constitucional liberal tradicional se emparenta en este punto con la teoría populista del poder constituyente, representada por Sieyès y Carl Schmitt. Según estos autores, el poder constituyente, en tanto que creador de normatividad, es un poder anterior y superior a la constitución que no puede ser regulado legalmente. Esta teoría confunde la atribución del poder constituyente al pueblo, que en su origen no deriva de una norma legal, con la expresión y manifestación de dicho poder, que necesariamente depende de canales institucionales que podrían ser establecidos con anterioridad a su aparición. ${ }^{3}$ En cualquier caso, esta teoría coincide con la teoría constitucional tradicional en relegar el ejercicio del poder constituyente a un momento excepcional y revolucionario de necesaria ruptura con la legalidad precedente.

Cabe mencionar que a pesar de la posición hegemónica del constitucionalismo occidental sobre este tema, un grupo reducido de constituciones en el mundo han buscado escapar al problema que representa tener un vacío legal en materia de reemplazos a la constitución. Algunas constituciones, particularmente en el contexto de regímenes parlamentarios, permiten que la legislatura ordinaria apruebe tanto reformas parciales como totales a la constitución, a veces estableciendo un procedimiento distinto para esto último. ${ }^{4}$ Sin embargo, hay dos escenarios en que esta salida podría no ofrecer una real solución. El primero es aquel en que la legislatura se opone al reemplazo de la constitución y la ciudadanía carece de instrumentos propios, como una iniciativa popular, para impulsar el proceso.

3 Ver en este respecto, Böckenförde (2000: 169). Carl Schmitt distingue entre la activación de la voluntad constituyente del pueblo, que depende de una decisión política que no puede ser mediada ni organizada por reglas constitucionales, de la ejecución de esa voluntad, que puede ser sujeta a procedimientos. A pesar de esta distinción, Schmitt considera que los procedimientos bajo los que se ejecuta la voluntad constituyente son establecidos basándose en prácticas históricas cambiantes que no corresponde reglamentar en la constitución. Ver Schmitt (1982: 93-103).

4 Este procedimiento puede consistir en realizar una nueva elección parlamentaria o someter la nueva constitución a ratificación popular. 
El segundo es aquel en que la legislatura favorece el cambio, pero este cuerpo no goza de legitimidad ante la ciudadanía. Por otra parte, hay también algunas constituciones, particularmente en América Latina, que prevén el llamado a una convención especial para el caso de reforma total o reemplazo de la constitución. ${ }^{5}$ Estas constituciones sí permiten una salida en el caso de que se requiera de un cuerpo constituyente especial, aunque es preciso observar que varias de estas mismas constituciones fueron en su momento creadas en ausencia de una previsión constitucional.

En el caso común en el que no hay regulación legal del proceso, esto no impide que el mismo sea implementado. Una vez que la demanda por una nueva constitución se expande entre la ciudadanía y permea a sectores relevantes de la elite política, tarde o temprano se dará inicio al proceso de elaboración de una nueva constitución. En este contexto, es obviamente insuficiente (y a menudo contraproducente) apelar al poder constituyente del pueblo como receta mágica para resolver los distintos desafíos que plantea esta situación. El involucramiento de los ciudadanos necesita de canales institucionales y las formas que se adopten pueden tener consecuencias muy relevantes tanto para la legitimidad de la nueva constitución como para la calidad y desempeño futuro del régimen democrático.

\section{ALTERNATIVAS EN LA REGULACIÓN INSTITUCIONAL DEL PROCESO CONSTITUYENTE}

Un proceso constituyente democrático implica varias etapas, que combinan distintas instancias de representación y de participación ciudadana. El primer momento consiste normalmente en la expresión de apoyo popular al reemplazo de la constitución. Esta expresión puede ser directa, por ejemplo votando a favor de iniciar el proceso en un referendo convocado por las autoridades, o indirecta, por medio del apoyo electoral mayoritario a un partido o coalición que propone sustituir la constitución vigente. Por otra parte, la expresión de apoyo popular al proceso puede ser formal, como es el caso de un referendo convocado utilizando mecanismos preexistentes, o informal, como sería una movilización social masiva a favor de reemplazar la constitución. Sea cual fuere el caso, la manifestación de una voluntad constituyente deber ser seguida de su ejecución por vías institucionales. Estas refieren a los mecanismos que se utilizarán para la discusión de los lineamientos o propuestas generales de reforma, la elaboración de un nuevo texto constitucional, y la aprobación y eventual ratificación del mismo.

Existen muchos detalles en un proceso constituyente. A los efectos de este ensayo me centraré en dos aspectos cuya definición es vital en un contexto democrático: la

5 Antes de 1978 previeron la convocatoria de una asamblea o convención constituyente en la región (en general para tratar reformas generales o ciertos artículos o principios, aunque a veces también para cualquier reforma parcial) la constitución Argentina de 1853, la de Costa Rica de 1949 (luego de la reforma de 1968), la de Guatemala de 1945, la de Honduras entre 1894 y 1936, y la de Uruguay de 1967. Actualmente regulan la convocatoria a una convención especial la constitución Argentina de 1994, la de Bolivia de 2009, la de Colombia de 1991, la de Ecuador de 2008, la de Guatemala de 1985, la de Nicaragua de 1987, la de Panamá de 1972 (luego de la reforma de 2004), la de Paraguay de 1992 y la de Venezuela de 1999. 
selección del órgano representativo que aprobará los cambios a la constitución y los mecanismos que involucran directamente a los ciudadanos en la creación de un nuevo texto constitucional.

\section{El órgano representativo: asamblea vs. legislatura constituyente}

Existen muchas variantes en la experiencia comparada en cuanto a los cuerpos colectivos de representación ciudadana que participan en un proceso constituyente. Sin embargo, los cuerpos más importantes encargados de aprobar una nueva constitución son las asambleas o convenciones constituyentes y las legislaturas ordinarias a quienes se les autoriza o asumen una función constituyente. ${ }^{6}$ Otros cuerpos colectivos pueden ocupar un lugar importante en la elaboración de una nueva constitución, pero sus funciones suelen limitarse a preparar propuestas o alternativas de reforma (como ocurre con las Comisiones Constitucionales), o bien deliberar y negociar el procedimiento y los lineamientos generales de reforma (como las Mesas Redondas y las Conferencias Nacionales). ${ }^{7}$

\section{Asambleas constituyentes}

En el derecho constitucional occidental, el mecanismo tradicional para canalizar institucionalmente el ejercicio del poder constituyente ha sido la convocatoria de una convención o asamblea, independiente de la legislatura ordinaria, cuya exclusiva función es la redacción y aprobación de un nuevo texto constitucional. Mientras que en el derecho constitucional americano la denominación clásica de este cuerpo ha sido la de convención constitucional (constitutional convention), en el derecho Francés y Europeo se la ha llamado asamblea constituyente (assemblée constituante). ${ }^{8}$ En América Latina, que es una de las regiones del mundo que más ha recurrido históricamente a estos cuerpos, se utiliza frecuentemente el nombre de asamblea o convención constituyente. ${ }^{9}$

La justificación de la asamblea constituyente (AC, de ahora en más) es clara y está fundada en la distinción entre poder constituyente y poder constituido. Debido a que la constitución es una creación del pueblo para actuar por medio de ella y para proteger sus derechos, la misma no puede ser alterada en lo fundamental por la legislatura ordinaria, sino por un cuerpo especial que represente a las preferencias ciudadanas en

6 Ver al respecto, Elster (2006).

7 En un análisis de 411 episodios de reemplazo constitucional que tuvieron lugar entre 1789 y 2005, Ginsburg, Elkins y Blunt (2009: 213) encontraron que en su vasta mayoría el órgano central responsable de la aprobación del texto final fue o bien una asamblea constituyente (103 casos) o bien una legislatura a la que se le otorgaron o asumió facultades constituyentes (178 casos).

8 Si bien las convenciones constitucionales y las asambleas constituyentes tienen la misma función -sancionar una nueva constitución- el adjetivo "constituyente" de las segundas suele tomarse como una atribución de soberanía y de rechazo a todo límite legal. Esto no ha sido siempre así en la práctica histórica, pero explica la animadversión que suele generar por parte de quienes abogan por un proceso controlado legalmente.

9 En una muestra de 160 procesos constituyentes celebrados entre 1780 y 2000, Mendez y Wheatley (2013: 28) encuentran que América Latina es la región que más frecuentemente ha usado asambleas constituyentes en el mundo. 
cuanto al contenido de la nueva constitución. ${ }^{10}$ Tanto por este mandato popular como por su posible integración, una AC puede generar varias ventajas desde el punto de vista de las credenciales democráticas de la nueva constitución.

Debido a que la AC tiene como responsabilidad exclusiva redactar una constitución, la elección directa de sus miembros (una modalidad común de integración en contextos democráticos) permite que los ciudadanos elijan delegados basándose en propuestas específicas de reforma y no solo siguiendo programas partidarios de carácter general. Por otra parte, una $\mathrm{AC}$ admite métodos de selección de delegados que pueden darle a esta un carácter más incluyente y plural que el que normalmente tiene una legislatura ordinaria. Por ejemplo, a diferencia de la naturaleza eminentemente partidaria que tienen las asambleas legislativas, es posible que en una AC se elijan o designen delegados independientes y se de cabida a grupos excluidos o miembros de la sociedad civil que carecen de pertenencia partidaria. ${ }^{11}$ También es posible que la asamblea adquiera un carácter directamente "ciudadano" haciendo que la totalidad o parte de sus miembros sean seleccionados de manera aleatoria de una muestra representativa de la sociedad. ${ }^{12}$

Sin embargo, en contextos de débil institucionalidad, una AC puede convertirse en un instrumento de desestabilización política e incluso de erosión del régimen democrático. Por ejemplo, debido a que la AC puede reclamar una legitimidad democrática superior a la de la legislatura, su coexistencia con esta última podría dar lugar a serios conflictos de competencia. Más aún, si la asamblea se autoproclama soberana podría incluso intervenir o usurpar funciones no solo de la legislatura, sino del poder judicial y otras instituciones independientes de control. De esta manera, una AC legitimada por el voto popular pero controlada por una única fuerza política podría servir para encubrir una captura arbitraria del poder estatal.

Que la AC cumpla un papel positivo o negativo para la creación de una constitución democrática depende fundamentalmente de la forma en que se resuelve su convocatoria, la selección de sus miembros y la regulación de sus funciones. Ante la falta de previsión de estos cuerpos en la constitución, las decisiones sobre estos puntos suelen suscitar intensos conflictos políticos y legales que involucran a todas las ramas del poder. ${ }^{13}$ La experiencia latinoamericana reciente nos ofrece un mapa de alternativas ante esta situación, que se pueden agrupar conceptualmente de acuerdo con la fuente de la que surge la regulación legal de la asamblea. La principal disyuntiva es si la regulación se hará por medio de una enmienda al procedimiento de reforma de la constitución vigente

10 Sobre el origen histórico de esta idea, ver Wood (1969: 306-343).

11 Por ejemplo, la convención constituyente elegida en 2010 en Islandia fue escogida sobre la base de candidatos ciudadanos sin apoyo partidario. En Colombia, si bien la asamblea elegida en 1990 se compuso mayoritariamente de candidatos de origen partidario, se reservaron cuatro asientos para miembros designados por grupos guerrilleros que abandonaron la lucha armada.

12 Entre 2012 y 2014 se reunió en Irlanda una convención, en la que dos terceras partes de sus miembros fueron ciudadanos seleccionados de manera aleatoria y una tercera parte políticos designados por sus partidos. Sobre esta y otras modalidades de asambleas constituyentes ciudadanas, ver Renwick (2014).

13 Por razones de espacio, sin embargo, me voy a centrar aquí en el poder legislativo y ejecutivo, dejando de lado la importante intervención de las cortes constitucionales. 
o por la creación de un procedimiento paralelo. Este procedimiento paralelo puede, a su vez, ser establecido por un acuerdo institucional entre el ejecutivo y la legislatura, un acuerdo político entre el gobierno y los principales partidos, o por decisión unilateral del ejecutivo.

La fuente de regulación legal de la AC muestra el grado de continuidad o ruptura que se buscó respecto de la constitución vigente y la colaboración que en su regulación tuvieron los distintos actores institucionales y políticos. El caso de Bolivia ejemplifica la salida más legalista. El proceso inició formalmente con una enmienda del año 2004 al procedimiento de reforma, con el fin de autorizar a la legislatura a convocar una constituyente y regular su funcionamiento y atribuciones en casos de reforma "total". ${ }^{14}$ Con base en esta enmienda, la legislatura sancionó en 2006 una ley de convocatoria donde se especificaba el mecanismo de elección, las funciones y atribuciones de la asamblea, e incluso su procedimiento de decisión. ${ }^{15}$ Un mayor grado de ruptura con la legalidad precedente lo representan los casos de Ecuador entre 1997 y 1998 y Colombia entre 1990 y $1991 .^{16}$

En Ecuador el proceso comienza con una consulta popular convocada por el presidente interino, en uso de facultades propias y con acuerdo del Congreso, para que la ciudadanía decida si autorizaba o no la convocatoria de una AC. Como resultado del apoyo popular a la asamblea, el Congreso aprobó una cláusula transitoria que se añadió a la constitución para regular la elección y funcionamiento de la constituyente. ${ }^{17}$ En el caso de Colombia, el proceso se inició con una convocatoria del gobierno, de dudosa legalidad y sin participación del Congreso, a una consulta popular para autorizar la elección de una AC. ${ }^{18}$ No obstante, una vez que la ciudadanía aprobó el llamado a la constituyente, el presidente recién elegido realizó un acuerdo con los líderes de todos los principales partidos con el fin de decidir en común los procedimientos de elección y funcionamiento de la asamblea.

Por último, tenemos los casos de Perú 1992-1993, Venezuela 1998-1999 y Ecuador 20072008. Estos fueron episodios no solo de ruptura legal radical, sino también de falta de acuerdo entre los actores políticos e institucionales acerca de la regulación de la asamblea. ${ }^{19}$ A diferencia del caso peruano y similar al caso de Colombia, en Ecuador y Venezuela el proceso comienza con una consulta popular, de cuestionable legalidad. Sin embargo, un elemento común a todos los casos de ruptura radical fue que el ejecutivo decidió unilateralmente el procedimiento de elección y el funcionamiento de la asamblea y lo

14 Hasta ese momento la constitución solo permitía reformas parciales a la constitución por medio de un procedimiento especial de aprobación parlamentaria.

15 Para una comparación de los casos de Bolivia, Ecuador y Venezuela, ver Sánchez Sandoval y Welp (2013).

16 Para una comparación de estos casos, ver Negretto (2013).

17 Esto significa que si bien se estableció un procedimiento paralelo al procedimiento de enmienda de la constitución vigente, se buscó de todas maneras darle una base constitucional.

18 El gobierno de Barco invocó poderes emergentes del estado de sitio que regía en el país para convocar la consulta.

19 A pesar de que en Perú imperaba un régimen formalmente autoritario al momento de iniciarse el proceso constituyente, la estrategia de implementación del mismo es claramente comparable con los casos de Ecuador y Venezuela, que eran generalmente considerados países democráticos en esos años. 
hizo de modo tal de beneficiar exclusivamente a su partido. Luego se sometió la nueva constitución a un referendo como forma de subsanar las irregularidades del proceso.

La diferencia clave entre los distintos episodios fue la existencia o no de un acuerdo institucional o político según el cual se reguló el proceso. Allí donde dicho acuerdo no existió, la AC fue cooptada por el partido de gobierno y se convirtió en su instrumento. Una característica compartida por los casos de ruptura radical fue que el partido del presidente carecía de apoyo significativo en la legislatura y la AC fue precisamente la plataforma utilizada para cambiar la distribución de fuerzas. En algún caso (Perú) la asamblea reemplazó directamente al Congreso, mientras que en otros (Ecuador y Venezuela) lo intervino y asumió sus funciones legislativas. No es casual que en todos estos casos la democracia representativa fue suspendida y resultó seriamente erosionada como consecuencia del proceso constituyente.

\section{Legislaturas constituyentes}

Si bien la teoría constitucional clásica exige que los órganos constituidos se mantengan al margen de realizar cambios constitucionales fundamentales, las legislaturas suelen participar frecuentemente en la redacción de una nueva constitución. En estos casos, es propio hablar de una "legislatura constituyente" (LC, de ahora en más). Esto ocurre en dos situaciones: cuando la legislatura es elegida con el encargo inicial de que redacte una nueva constitución o cuando habiendo sido elegida para funcionar como órgano legislativo ordinario, asume funciones constituyentes. Estas funciones constituyentes, a su vez, pueden ser ejercidas con base en un procedimiento de reforma preexistente que la habilita al reemplazo de la constitución, o bien por medio de una decisión política que le otorga a la legislatura esa tarea al margen del procedimiento de enmienda.

La elección de una legislatura con el mandato popular de redactar una constitución y luego continuar sus funciones legislativas ordinarias es un procedimiento común durante la transición de un régimen autoritario a uno democrático. Este ha sido el caso de varios procesos constituyentes en transiciones a la democracia muy conocidas en el mundo, como las de España, Polonia o Sudáfrica. También se ha utilizado a menudo en varios países de América Latina, como Brasil (en 1946 y 1986), Nicaragua (1984), República Dominicana (1966) o Venezuela (1961).

En el contexto de un régimen democrático ya constituido, la intervención de la legislatura en la adopción de una nueva constitución puede tener lugar como consecuencia de un procedimiento de enmienda preexistente que le autoriza a reformar de forma total la constitución vigente. Este es por ejemplo el caso de Suiza, Suecia o Finlandia, cuyas constituciones permiten que el parlamento, por medio de un procedimiento especial, pueda no solo enmendar la constitución vigente, sino también aprobar una nueva constitución. Los parlamentos de estos países han utilizado estos poderes para sancionar nuevas constituciones en 1999, 1974 y 2000, respectivamente. ${ }^{20}$ En América Latina ha 
sido el caso de Uruguay, que adoptó varios aspectos del proceso de enmienda de la constitución Suiza.

Por último, tenemos el caso de legislaturas que en función de una decisión política del gobierno o de los distintos partidos que la componen asumen funciones constituyentes sin haber sido elegidas para ese propósito ni tampoco contar con un claro respaldo legal en la constitución vigente. Este ha sido el caso de la sanción de una nueva constitución en Hungría en 2011, donde si bien existía una base legal en la constitución precedente para crear una nueva constitución por parte del parlamento, la misma no fue respetada. ${ }^{21}$

Desde el punto de vista de su legitimidad democrática, una LC suele tener una representación exclusiva o predominante partidaria, lo que la hace un órgano potencialmente menos incluyente que una AC. Sin embargo, cabe hacer distinciones. Una legislatura elegida al comienzo de una transición para elaborar una nueva constitución, no difiere radicalmente de una convención constituyente. Ambas son elegidas por los ciudadanos con el mandato de hacer una nueva constitución, lo que permite que la elección del cuerpo se funde explícitamente en propuestas alternativas de reforma.

El caso es distinto cuando una legislatura ordinaria asume funciones constituyentes sin un mandato electoral precedente. Si lo hace de acuerdo con una autorización constitucional, es necesario distinguir si el procedimiento contempla que la aprobación final de la constitución se realice por medio de un nuevo parlamento elegido al efecto. De verificarse este requisito, como debe ocurrir según la constitución Suiza (cuando hay diferencias entre las cámaras o la iniciativa parte de la ciudadanía) o Finlandesa (en todo caso), la LC tampoco difiere demasiado de una convención especial. En cambio, si la legislatura ordinaria asume la función constituyente por medio de una decisión política al margen o en contra del procedimiento establecido y sin realizar una nueva elección, el cuestionamiento de legitimidad democrática es más severo, pues sus legisladores nunca fueron autorizados para sancionar una nueva constitución.

Dentro de un orden democrático constituido, el problema más serio de legitimación en la utilización de legislaturas constituyentes (en cualquier modalidad) ocurre cuando los ciudadanos tienen bajos niveles de confianza en los legisladores. Y este problema se agudiza cuando la reforma del propio parlamento es una de las principales razones por las que se quiere redactar una nueva constitución. En América Latina, el recurso reciente a las asambleas constituyentes estuvo fundado en estos dos problemas.

La constitución Venezolana de 1961 contemplaba en su artículo 246 un proceso de reforma total en el que el Congreso podía sancionar una nueva constitución por medio de un procedimiento especial que incluía someter la reforma a ratificación popular. Sin embargo, cuando a comienzos de los 90 se comenzó a discutir la necesidad de reemplazar la constitución vigente, incluso aquellos que apoyaban una estrategia de continuidad legal argumentaban que la baja aprobación ciudadana del Congreso hacía necesario 
convocar una AC. ${ }^{22}$ En el caso de Colombia, aunque inicialmente el gobierno de Barco buscaba una reforma profunda de la constitución mediante el Congreso y por medio del procedimiento de enmienda vigente, se fue abandonando la hipótesis a medida que quedó claro que dicha institución requería ser reformada y que la misma no estaba dispuesta a permitir su propia reforma. ${ }^{23}$

\section{Participación ciudadana: testimonial o sustantiva, plebiscitaria o deliberativa}

El involucramiento ciudadano en un proceso constituyente no se agota en la selección y conformación de un órgano representativo encargado de adoptar la nueva constitución. Existen varios canales posibles de participación ciudadana directa. Algunos pueden tener lugar antes de que se elabore un proyecto, como es el caso de los cabildos abiertos, los foros participativos, o las comisiones constitucionales o comités parlamentarios que llevan a cabo consultas por medio de audiencias, encuestas u otros medios. También se han organizado procesos de participación popular durante la elaboración del proyecto de constitución, por medio de la presentación de propuestas provenientes de la sociedad civil. Finalmente, la participación puede tener lugar con posterioridad a la aprobación de un nuevo texto que se somete a ratificación por referendo antes de entrar en vigencia.

Si bien todos estos mecanismos pueden utilizarse para reforzar la legitimidad democrática del proceso, es necesario hacer varias precisiones. Algunos canales de participación, como las consultas públicas o la recepción de propuestas de la sociedad civil, tienden a ser puramente testimoniales. Estas suelen dejar registro de las posiciones o peticiones formuladas por distintas personalidades o grupos sociales, sin que las mismas entren formalmente en el proceso de deliberación y elaboración de la nueva constitución. Esto ocurre tanto por el poder de agenda y la discrecionalidad de quienes reciben y seleccionan las propuestas como por la imposibilidad real y la inconveniencia de tomar en cuenta todas las opiniones formuladas en materia de reforma. El problema es que entonces el resultado final del proceso, que frecuentemente refleja las negociaciones y acuerdos entre actores partidarios, puede ser visto por ciertos ciudadanos y grupos con mayor desconfianza que si no se hubiese implementado un proceso formal de consulta. Si bien la participación ciudadana puede ser un bien en si misma (y esa es la virtud central que exaltan su defensores), la expectativa de todo proceso participativo es que las opiniones o propuestas que proveen los ciudadanos sean tenidas en cuenta a la hora de redactar un proyecto final de constitución.

Frente a los inconvenientes que pueden presentar las consultas y la recepción de propuestas, uno de los mecanismos más frecuentes de participación popular en procesos constituyentes es la ratificación de la nueva constitución por medio de un referendo. ${ }^{24}$

22 La estrategia era enmendar el procedimiento de enmienda para contemplar la posibilidad de convocar a una AC y que se legitimara dicha enmienda por medio de una ratificación popular. Ver Brewer Carias (2002).

23 Sobre este caso, ver Negretto (2012).

24 De una muestra de 413 casos de cambio constitucional ocurridos entre 1800 y 2000, Ginsburg, Blunt y Elkins (2008: 377) encuentran que la ratificación popular del nuevo texto constitucional es no solo el procedimiento más frecuente de participación ciudadana, sino que el número de casos que lo usan crece desde 1950. 
No obstante, la legitimidad democrática de los referendos ratificatorios es dudosa cuando se utilizan como el canal exclusivo o predominante de participación popular. Las constituciones sancionadas por dictaduras, como la de Chile de 1980 y la de Panamá de 1972, o las que surgen de procesos centralizados y de corte autoritario, como la de Chile de 1925 o la de Francia de 1958, tienden a recurrir a la ratificación plebiscitaria como forma de encubrir bajo una fachada participativa lo que en esencia fue un proceso antidemocrático. Algo parecido ocurre cuando el referendo se utiliza luego de un proceso controlado por el partido de gobierno, como fue el caso de Perú en 1993, Venezuela en 1999 o Ecuador en 2008.

El referendo parte de una concepción unitaria y homogénea del pueblo que como tal solo es capaz de adoptar decisiones binarias por medio del principio de mayoría. Por ello ocurre que esta forma de participación, si es usada en exclusividad o de manera central, es poco conducente a la deliberación pública necesaria para formar preferencias informadas en torno a la nueva constitución. Todo proceso deliberativo requiere ser realizado en un cuerpo representativo incluyente y de carácter plural en donde las decisiones no necesariamente deben hacerse por medio del principio de mayoría. Es más, desde este punto de vista, cuantas más instancias representativas de deliberación intervengan en la elaboración de una constitución mejor será la calidad de la deliberación y mejor fundamentada será la formación de preferencias de los ciudadanos respecto de la nueva constitución. ${ }^{25}$ De otra manera, la aprobación de la constitución se torna en un plebiscito que bajo ciertas condiciones es fácilmente manipulable.

Una última apreciación, vinculada a lo anterior, es que ningún mecanismo de participación popular directa debería usarse para suplir las deficiencias representativas del órgano constituyente. Si la legitimidad del cuerpo constituyente es fuertemente cuestionada por la ciudadanía, difícilmente las consultas públicas, la presentación de peticiones, o los referendos sean capaces de superar esa falencia. Es por esa razón que la selección del cuerpo representativo constituyente y los canales de participación ciudadana no deben verse como dos dimensiones separadas sino como partes complementarias de un mismo proceso.

\section{REFLEXIONES SOBRE EL CASO CHILENO}

A pesar de la estabilidad política y económica que a nivel regional ha experimentado Chile desde su transición a la democracia, su sistema político y económico ha venido sumando en los últimos años varios cuestionamientos provenientes de la sociedad. Entre los más importantes se encuentran la desigualdad social, el veto institucional de minorías poderosas y la existencia de una elite partidaria alejada del ciudadano común. Estos problemas, a su vez, encuentran una referencia causal en la actual constitución, que si bien permitió el proceso de democratización y reformas políticas importantes, tiene un origen autoritario y se funda en concepciones políticas y económicas excluyentes. En 
este contexto, la candidata a presidenta Michelle Bachelet ganó la elección presidencial de 2013 con la propuesta de que Chile necesita una nueva constitución que expanda los derechos individuales y colectivos, reduzca el veto de minorías en los procesos de decisión y establezca nuevos mecanismos de participación ciudadana. Asimismo, aseguró que esta constitución surgirá de un proceso "democrático, institucional y participativo".

Aunque la discusión sobre los contenidos de la nueva constitución será un aspecto central del proceso, la tarea inmediata es la definición del procedimiento según el cual se redactará la nueva constitución. El artículo 127 de la constitución actual solo prevé un procedimiento general de reforma, sin contemplar específicamente la posibilidad de reforma total o reemplazo de la constitución. El interrogante entonces es cuál sería el cuerpo constituyente y los mecanismos de participación popular más adecuados para lograr los cambios propuestos en un proceso que sea democrático e institucional, y a la vez factible teniendo en cuenta la situación política actual del país.

La idea de que el proceso constituyente sea institucional implica lógicamente que su regulación legal debiera surgir de un acuerdo entre el ejecutivo y el Congreso. En teoría, este acuerdo podría servir para optar por una $\mathrm{AC}$, regulada mediante una reforma o añadido al procedimiento de enmienda actual o por una serie de reglas paralelas al mismo. ${ }^{26}$ Esta convención, a su vez, podría tener una naturaleza fuertemente democrática y participativa si adoptara mecanismos de selección de delegados que fueran más allá de una representación puramente partidaria. Por otra parte, al estar menos vinculada a los poderes constituidos y a los partidos tradicionales, una convención especial sería el instrumento más adecuado para lograr los cambios profundos a la constitución que propone el gobierno. ${ }^{27}$ Todo indica, sin embargo, que este camino es poco viable.

La derecha política y los sectores económicos más cercanos a la misma ya han adelantado su posición contraria a una AC. Debido a que cualquier acuerdo entre presidencia y Congreso le daría a la oposición capacidad de veto institucional, quedaría descartado convocar una asamblea de manera consensual. ${ }^{28}$ Es cierto que la oposición podría ceder, si experimentara una fuerte presión política y social a favor de una constituyente. En todos los casos recientes en América Latina donde se dio paso a la convocatoria de una AC en ausencia de previsión legal, existieron inicialmente importantes sectores políticos y económicos opuestos a la misma. Sin embargo, su resistencia se fue debilitando fruto de tres factores: la percepción compartida por la elite y la ciudadanía de que el país vivía una profunda crisis política, el surgimiento de una extendida movilización social a favor de la AC y el apoyo de los medios de comunicación a dicha opción. Ninguna de estas condiciones se visualizan hoy claramente en Chile.

Queda entonces la posibilidad de utilizar el parlamento como LC. En principio, esto no debe ser visto como una opción de menor calidad. La literatura empírica de carácter

26 Soto Barrientos (2014: 421) sugiere la posibilidad de incluir el llamado a la constituyente para una reforma total en un capítulo aparte de la constitución.

27 Sobre este punto, ver Atria (2013: 80-84).

28 Este sería particularmente el caso de una enmienda al proceso de reforma, que según el artículo 127 requiere de dos terceras partes del voto de diputados y senadores. 
comparado no ha encontrado diferencias significativas entre el uso de asambleas o legislaturas constituyentes para el logro de varios objetivos deseables, como la durabilidad futura de la nueva constitución, la reducción de conflictos, o la profundización de la democracia. ${ }^{29}$ Por otra parte, y como hemos visto, tampoco hay una ventaja incondicional de la AC por sobre la LC desde el punto de vista de la legalidad y legitimidad democrática del proceso constituyente. Todo depende de qué tipo de AC o LC se utilice.

La pregunta entonces es qué modelo de LC podría satisfacer al mismo tiempo criterios de institucionalidad y legitimidad democrática. A pesar de que los votantes favorecieron en 2013 a una coalición que apoyaba reemplazar la constitución de 1980, la legislatura actual no fue elegida con el mandato explícito de redactar una nueva constitución. Por tanto, y debido a que no hay actualmente en Chile elecciones legislativas intermedias, la única posibilidad de utilizar una legislatura con mandato popular constituyente sería postergar la sanción de la nueva constitución hasta la elección del próximo Congreso. Esto daría mayor legitimidad al cuerpo constituyente, con la ventaja adicional de que habiéndose abandonado recientemente el cuestionado sistema binominal, la legislatura podría elegirse según el nuevo sistema proporcional. Para el gobierno, sin embargo, esto implicaría incumplir la promesa de producir una nueva constitución durante su mandato.

Otra alternativa es que el actual Congreso, sea utilizando el procedimiento de enmienda existente o bien introduciendo reglas paralelas, sancione una serie de reformas que se presenten como una nueva constitución. Esta opción sería sin duda la que mayor continuidad legal ofrecería y que probablemente sería aceptada por la oposición. Su principal riesgo, sin embargo, reside en la baja aprobación ciudadana que podría tener en ese caso el cuerpo constituyente. La ciudadanía considera al Congreso Chileno y a los partidos que lo componen como instituciones muy poco representativas. Según Latinobarómetro, la proporción de chilenos que manifiestan tener mucha o bastante confianza en el Congreso y los partidos políticos bajó del 43 al 21\%, y del 34 al 15\%, respectivamente, entre 1995 y 2013. Este deterioro es incluso pronunciado en el contexto latinoamericano, donde los parlamentos y los partidos tienen los niveles más bajos de confianza ciudadana a nivel mundial. ${ }^{30}$ Por último, es preciso tener en cuenta que de ser el Congreso existente quien sancione finalmente las reformas, pudiera ser que el contenido de las mismas sea mucho menos profundo y radical que lo que ha prometido el gobierno.

De utilizarse el actual Congreso como cuerpo constituyente, es posible encontrar fórmulas que refuercen la legitimidad democrática del proceso. Por ejemplo, la formulación de propuestas de reforma o los lineamientos generales de la nueva constitución podrían surgir de una asamblea consultiva ciudadana, o de una conferencia nacional o comisión constitucional representativa de distintos sectores. ${ }^{31}$ También se podría recurrir a un referendo popular para ratificar el texto final de la constitución. Sin embargo, cualquiera 
sea la combinación, es preciso tener en cuenta que no es fácil equilibrar la institucionalidad con el carácter democrático y participativo del proceso.

Un proceso constituyente puramente institucional podría terminar utilizando las instituciones existentes y restando por tanto características democráticas y participativas al mismo. Por otra parte, no es normalmente viable mantener una impecable continuidad legal y realizar transformaciones profundas al contenido actual de una constitución. Así como un proceso de ruptura radical puede producir cambios trascendentales, pero al costo de desestabilizar el régimen democrático, un proceso estrictamente legal y continuista mantendría la estabilidad del sistema al costo de hacer cambios superficiales. El dilema constituyente consiste en cómo elaborar una nueva constitución que permita realizar reformas profundas, dé lugar a una participación ciudadana que supere las deficiencias de legitimidad de la constitución vigente y lo haga sin que esta participación se convierta en excusa para romper radicalmente con la legalidad. Desafortunadamente, no es siempre posible lograr todos estos objetivos al mismo tiempo y con la misma plenitud.

\section{REFERENCIAS}

Atria, Fernando. 2013. La Constitución Tramposa. Santiago de Chile: LOM.

Auditoría a la Democracia: más y mejor democracia para un Chile inclusivo 2014. Santiago de Chile: PNUD. Böckenförde, Ernst. 2000. Estudios sobre el Estado de Derecho y la democracia. Madrid: Trotta.

Brewer Carías, Allan. 2002. Golpe de Estado y proceso constituyente en Venezuela. Mexico: UNAM.

Elkins, Zachary, Tom Ginsburg y Justine Blount. 2008. “The Citizen as Founder: Public Participation in Constitutional Approval". Temple Law Review 81 (2): 361-382.

Elster, Jon. 2006. "Legislatures as Constituent Assemblies", en Richard W. Bauman y Tsvi Kahna (eds.), The Least Examined Branch: The Role of Legislatures in the Constitutional State. New York: Cambridge University Press.

Ginsburg, Tom. 2014. “¿Fruto de la Parra Envenenada? Algunas observaciones comparadas sobre la constitución chilena." Estudios Públicos 133: 1-36.

Ginsburg, Tom, Zachary Elkins y Justine Blount. 2009. "Does the Process of Constitution-Making Matter?". American Review of Law and Society 5: 201-223.

Landau, David. 2013. “Abusive Constitutionalism". UC Davis Law Review 47: 1-58.

Madison, James, Alexander Hamilton y John Jay. 1788 [1987]. The Federalist Papers. London: Penguin.

Negretto, Gabriel. 2013. Making Constitutions: Presidents, Parties, and Institutional Choice in Latin America. New York: Cambridge University Press.

_2012. "Replacing and Amending Constitutions. The Logic of Constitutional Change in Latin America". Law \& Society Review 46 (4): 749-779.

Oliver, Dawn y Carlo Fusaro. 2011. How Constitutions Change: A Comparative Study. Portland: Hart Publishing.

Paine, Thomas [1791] 1995. "Rights of Man". En Thomas Paine: Collected Writings, 431-662. New York: Library of America.

Renwick, Alan. 2014. After the Referendum: Options for a Constitutional Convention. London: The Constitution Society.

Sánchez Sandoval, Nina y Yanina Welp. 2013., "Legality and Legitimacy: Constituent Power in Venezuela, Bolivia, and Ecuador". En Patterns of Constitutional Design: The Role of Citizens and Elites in Constitution Making, Jonathan Wheatley y Fernando Mendez (eds.), 103-118. London: Ashgate.

Schmitt, Carl. 1982. Teoría de la Constitución. Madrid: Alianza Universidad.

Soto Barrientos, Francisco. 2014. "AC: La Experiencia Latinoamericana y el Actual Debate en Chile. Estudios Constitucionales 12 (1): 397-428. 
Tierney, Stephen. 2012. Constitutional Referendums: The Theory and Practice of Republican Deliberation. London: Oxford University Press.

Widner, Jennifer. 2008. "Constitution Writing in Post-Conflict Settings: Overview". William \& Mary Law Review 49 (4): 1513-1541.

Wheatley, Jonathan y Fernando Mendez. 2013. Patterns of Constitutional Design: The Role of Citizens and Elites in Constitution-Making. London: Ashgate.

Wood, Gordon. 1969. The Creation of the American Republic: 1776-1787. New York: Norton.

Gabriel L. Negretto es Profesor de la División de Estudios Políticos del Centro de Investigación y Docencia Económicas.

E-mail: gabriel.negretto@cide.edu 
